\title{
FASILITAS PEMBELAJARAN DAN RUANG KOMUNITAS DIGITAL
}

\author{
Henry Halim ${ }^{1)}$, Dewi Ratnaningrum ${ }^{2)}$ \\ 1) Program Studi S1 Arsitektur, Fakultas Teknik, Universitas Tarumanagara, henryhalim37@outlook.com \\ 2) Program Studi S1 Arsitektur, Fakultas Teknik, Universitas Tarumanagara, dewir@ft.untar.ac.id
}

\begin{abstract}
Abstrak
Dewasa ini, generasi millennials menjadi topik yang cukup hangat di kalangan masyarakat, mulai dari segi pendidikan, teknologi maupun moral dan budaya. Millennials atau kadang juga disebut dengan generasi $Y$ adalah sekelompok orang yang lahir setelah Generasi $X$, yaitu orang yang lahir pada kisaran tahun 1980- 2000an. Generasi millennials memiliki ciri khas yaitu, mereka sangat kreatif di bidang teknologi digital. Dewasa ini perkembangan terhadap ekonomi kreatif sangatlah pesat. Kontribusi ekonomi kreatif pada perekonomian nasional semakin nyata. Nilai tambah yang dihasilkan ekonomi kreatif juga mengalami peningkatan setiap tahun. Pertumbuhan sektor ekonomi kreatif sekitar 5,76 \%. Artinya berada di atas pertumbuhan sektor listrik, gas dan air bersih, pertambangan dan penggalian, pertanian, peternakan, kehutanan dan perikanan, jasa-jasa dan industri pengolahan. Ekonomi Kreatif adalah Pilar Perekonomian Bangsa. Terlebih di bidang Blog video, blog video banyak diminati oleh generasi millennials dan pekerjaan sebagai blog video, dan juga cocok bagi generasi millennials karena sifat mereka yang kreatif dan cara kerja yang bersifat fleksibel. Permasalahannya adalah banyak generasi millennials yang minim dengan ilmu tentang membuat sebuah konten yang menarik. Dengan demikian dibuatlah proyek Fasilitas Pembelajaran Dan Ruang Komunitas Digital yang dapat mewujudkan cita-cita generasi millennials yang minim akan kreatifitas di bidang tersebut. Dengan metode Survey lapangan, shape grammar, dan green architecture, proyek ini dapat menjadi proyek yang berguna bagi lingkungan sekitarnya dan dapat menjadi wadah yang bermanfaat bagi generasi millennials agar mampu menemukan dan menganalisa permasalahan yang terjadi pada perkembangan teknologi informasi dan perkembangan ekonomi kreatif di bidang blog video.
\end{abstract}

Kata kunci: blog; edukasi; kreatif; millennials; Muara Karang

\begin{abstract}
Today, generation of millennials is a topic that is quite warm among the people, starting from the aspect of education, technology and morals and culture. Millennials or sometimes also called generation $Y$ are a group of people born after Generation X, namely people born in the 1980 s and 2000s. Generation of millennials has a characteristic that is, they are very creative in the field of digital technology. Today the development of the creative economy is very rapid. The contribution of the creative economy to the national economy is increasingly evident. The added value generated by the creative economy also increases every year. The growth of the creative economy sector is around $5.76 \%$. This means that it is above the growth of the electricity, gas and clean water sector, mining and quarrying, agriculture, livestock, forestry and fisheries, services and processing industries. Creative Economy is the Pillar of the Nation's Economy. Especially in the field of video blogging, video blogs are mostly asked by generations of millennials and jobs as video blogs, and are also suitable for generations of millennials because of their creative nature and flexible ways of working. The problem is that many generations of millennials are lacking in the knowledge of making interesting content. Thus the Digital Community Learning and Space Facilities project was created which can realize the ideals of the millennials generation that lack creativity in the field. With the method of field survey, shape grammar, and green architecture, this project can be a useful project for the surrounding environment and can be a useful forum for millennials to be able to find and analyze problems that occur in the development of information technology and the development of creative economics in the field of blogs video.
\end{abstract}

Keywords: blog; education; creative; millennials; Muara Karang 


\section{PENDAHULUAN}

Dewasa ini, generasi millennials menjadi topik yang cukup hangat di kalangan masyarakat, mulai dari segi pendidikan, teknologi maupun moral dan budaya. Millennials atau kadang juga disebut dengan Generasi Y adalah sekelompok orang yang lahir setelah Generasi X, yaitu orang yang lahir pada kisaran tahun 1980-2000an. Millennials sendiri dianggap spesial karena generasi ini sangat berbeda dengan generasi sebelumnya, apalagi dalam hal yang berkaitan dengan teknologi.Kemajuan teknologi adalah sesuatu yang tidak bisa dihindari dalam kehidupan ini, karena kemajuan teknologi akan berjalan sesuai dengan kemajuan ilmu pengetahuan. Setiap inovasi diciptakan untuk memberikan manfaat positif bagi kehidupan manusia. Teknologi juga memberikan banyak kemudahan, serta sebagai cara baru dalam melakukan aktivitas manusia. Kemajuan Teknologi juga memiliki dampak positif dan negatif apabila tidak dipergunakan dan dimanfaatkan dengan baik dan benar. Arus informasi saat ini menjadi sangat cepat, bahkan cenderung tidak terkontrol hingga saat ini.

Dewasa ini perkembangan terhadap ekonomi kreatif sangatlah pesat. Kreativitas akan mendorong inovasi yang menciptakan nilai tambah lebih tinggi. Nilai tambah yang dihasilkan ekonomi kreatif juga mengalami peningkatan setiap tahun. Pertumbuhan sektor ekonomi kreatif sekitar 5,76 \%. Artinya berada di atas pertumbuhan sektor listrik, gas dan air bersih, pertambangan dan penggalian, pertanian, peternakan, kehutanan dan perikanan, jasa-jasa dan industri pengolahan. Ekonomi Kreatif adalah Pilar Perekonomian Bangsa. Seperti contoh di perkembangan industri kreatif kerajinan, Memiliki sebuah vlog (Video Blog) adalah hal yang menyenangkan karena dapat berbagi apapun yang disukai oleh vlogger tersebut, dan kalau serius dalam merawat $v$ log juga bisa mendapatkan penghasilan yang layak dari vlog. Oleh karena itu pada era sekarang ini menjadi seorang vlogger bukanlah satu hal yang asing lagi karena menjadi seorang vlogger merupakan pekerjaan yang menyenangkan, bersifat terbuka, kreatif, invoatif.

Permasalahan yang ada adalah kaum menengah ke bawah merupakan kaum yang "memiliki keterbatasan di bidang ilmu dan teknologi", oleh karena itu mereka sangat sulit berkembang di bidang ini. Diperlukan sebuah wadah / tempat dimana kaum manapun bisa belajar mengenai teknologi, maupun konten-konten yang berhubungan dengan video blog. Dengan disediakannya wadah bagi mereka untuk belajar, maka semua orang dapat memulai membuat konten-konten yang ada di video blog dengan baik dan benar. Dengan ini terbentuklah ide, bagaimana perancangan sebuah bangunan community space yang baik dan bresifat permeabilitas ? dan Bagaimana menciptakan raung publik yang baik untuk bersosialisasi bagi generasi millennials?, serta mampu menemukan dan menganalisa permasalahan yang terjadi pada perkembangan teknologi informasi dan perkembangan ekonomi kreatif di bidang Video Blogging. Mampu memaparkan kebutuhan dari permasalahan yang ada pada generasi millennial khusunya di bidang Video Blogging.

\section{KAJIAN LITERATUR}

Generasi adalah suatu konstruksi sosial dimana didalamnya terdapat sekelompok orang yang memiliki kesamaan umur dan pengalaman historis yang sama. (Manheim, 1952). Individu yang menjadi bagian dari satu generasi, adalah mereka yang memiliki kesamaan tahun lahir dalam rentang waktu 20 tahun dan berada dalam dimensi sosial dan dimensi sejarah yang sama. (Manheim, 1952). Dalam beberapa tahun terakhir definisi generasi telah berkembang, salah satunya adalah definisi menurut (Kupperschimdt's, 2000) yang mengatakan bahwa generasi adalah sekelompok individu yang mengidentifikasi kelompoknya berdasarkan kesamaan tahun kelahiran, umur, lokasi, dan kejadian - kejadian dalam kehidupan kelompok individu tersebut yang memiliki pengaruh signifikan dalam fase pertumbuhan mereka.

Dalam literatur tentang perbedaan generasi digunakan kriteria yang umum dan bisa diterima secara luas diberbagai wilayah, dalam hal ini kriteria yang dipakai adalah tahun kelahiran dan peristiwa - peristiwa yang terjadi secara global (Twenge, 2006). Beberapa hasil penelitian secara konsisten membandingkan perbedaan generasi, denga sampel mulai dari tahun 1950an sampai 
dengan awaltahun 2000, menunjukkan perbedaan karakteristik dari 3 kelompok generasi, yaitu generasi baby boomers, generasi $X$ dan generasi $Y$ (Millennial), salah satunya adalah penelitian dari Lancaster \& Stillman (2002), yang memberikan hasil sebagai berikut :

\begin{tabular}{|c|c|c|c|}
\hline FAKTOR & BABY BOOMERS & GENERATION XERS & $\begin{array}{l}\text { MILLENNIALS } \\
\text { GENERATIONS }\end{array}$ \\
\hline ATTITUDE & OPTIMIS & SKEPTIS & REALITIS \\
\hline OVERVIEW & $\begin{array}{l}\text { Generasi ini percaya pada } \\
\text { adanya peluang, dan } \\
\text { seringkali terlalu idealis } \\
\text { untuk membuat } \\
\text { perubahan positif didunia. } \\
\text { Mereka juga kompetitif } \\
\text { dan mencari cara untuk } \\
\text { melakukan perubahan } \\
\text { dari sistem yang sudah } \\
\text { ada }\end{array}$ & $\begin{array}{l}\text { Generasi yang tertutup, } \\
\text { sangat independen dan } \\
\text { punya potensi, tidak } \\
\text { bergantung pada orang } \\
\text { lain untuk menolong } \\
\text { mereka }\end{array}$ & $\begin{array}{l}\text { Sangat menghargai } \\
\text { perbedaan, lebih } \\
\text { memilih bekerja sama } \\
\text { daripada menerima } \\
\text { perintah, dan sangat } \\
\text { pragmatis ketika } \\
\text { memecahkan } \\
\text { persoalan }\end{array}$ \\
\hline $\begin{array}{l}\text { WORK } \\
\text { HABITS }\end{array}$ & $\begin{array}{l}\text { Punya rasa optimis yang } \\
\text { tinggi, pekerja keras yang } \\
\text { menginginkan } \\
\text { penghargaan secara } \\
\text { personal, percaya pada } \\
\text { perubahan dan } \\
\text { perkembangan diri } \\
\text { sendiri }\end{array}$ & $\begin{array}{l}\text { menyeimbangkan antara } \\
\text { pekerjaan dengan } \\
\text { kehidupan, bersifat } \\
\text { informal, mengandalkan } \\
\text { diri sendiri, menggunakan } \\
\text { pendekatan praktis dalam } \\
\text { bekerja, ingin bersenang - } \\
\text { senang dalam bekerja, }\end{array}$ & $\begin{array}{l}\text { Memiliki rasa optimis } \\
\text { yang tinggi, fokus } \\
\text { pada prestasi, } \\
\text { percaya diri, percaya } \\
\text { pada nilai-nilai moral } \\
\text { dan sosial, } \\
\text { menghargai adanya } \\
\text { keragaman }\end{array}$ \\
\hline
\end{tabular}

Tabel 1. Karakteristik Kelompok Tiga Generasi

Sumber: Lancaster \& Stillman, 2002

\section{Pengertian Teknologi Informasi}

Perkembangan peradaban manusia diiringi dengan perkembangan cara penyampaian informasi yang selanjutnya dikenal dengan istilah (Teknologi Informasi ). Pada awalnya Teknologi Informasi dikembangkan manusia pada masa pra sejarah dan berfungsi sebagai sistem untuk pengenalan bentuk-bentuk yang mereka kenal, mereka menggambarkaninformasi yang mereka dapatkan pada dinding-dinding gua, tentang berburu dan binatang buruannya. Sampai saat ini teknologi informasi terus terus berkembang tetapi penyampaian dan bentuknya sudah lebih modern. Menurut Bambang

Warsita (2008) teknologi informasi adalah sarana dan prasarana (hardware, software, useware) sistem dan metode untuk memperoleh, mengirimkan, mengolah, menafsirkan, menyimpan, mengorganisasikan, dan menggunakan data secara bermakna. Hal yang sama juga di ungkapkan oleh Lantip dan Rianto (2011) teknologi informasi diartikan sebagai ilmu pengetahuan dalam bidang informasi yang berbasis komputer dan perkembanganya sangat pesat. Hamzah B. Uno dan Nina Lamatenggo (2011) juga mengemukakan teknologi informasi adalah suatu teknologi yang digunakan untuk mengolah data.

\section{Pengertian Tipologi}

Tipologi adalah suatu studi yang berkaitan dengan tipe dari beberapa objek yang memiliki jenis yang sama.Tipologi merupakan sebuah bidang studi yang mengklasifikasikan, mengkelaskan, mengelompokkan objek dengan ciri khas struktur formal yang sama dan 
kesamaan sifat dasar ke dalam tipe-tipe tertentu dengan cara memilah bentuk keragaman dan kesamaan jenis. Aspek klasifikasi dalam pengenalan tipologi mengarah pada usaha untuk mengklasifikasikan, mengkelaskan, mengelompokkan objek berdasarkan aspek-aspek/kaidahkaidah tertentu. Aspek-aspek yang dapat diklasifikasikan dapat berupa fungsi, bentuk, maupun gaya. Tipologi akan menjadi metode perancangan dalam merancang sebuah working space dimana working space memiliki perkembangan yang cukup signifikan yang dipengaruhi oleh prilaku penggunanya. Oleh karena itu tipologi sangat cocok dalam rancangan design ruang maupun ekseterior. Bukan hanya working space tipologi juga dapat diterapkan di ruang diskusi yang akan dikembangkan di proyek Vlogger Community Space and Creative Learning.

\section{Pengertian Kantor}

Kantor/kan?tor/ adalah 1 balai (gedung, rumah, ruang) tempat mengurus suatu pekerjaan (perusahaan dan sebagainya); 2 tempat bekerja; bank kantor (perusahaan) yang mengurus soal pinjam- meminjam uang, tabungan, dan sebagainya.

\section{Tipologi Kantor}

Penelitian menemukan bahwa orang-orang 'tahu tetangga mereka' dalam jarak 8 hingga 10 $\mathrm{m}$ di dalam tempat kerja. Komunitas kecil dan terkendala. Di kantor tradisional orang-orang bergerak dengan lift tertutup, seringkali hanya antara pintu masuk gedung dan lantai mereka. Makanan dan minuman terbatas pada tempat penjualan atau 'tempat minum teh' dan restoran atau kafetaria sentral dan ruang sirkulasi dianggap tidak efisien dan dijaga agar tetap minimum.

\begin{tabular}{llll}
\hline ERA & OFFICE 1970 & OFFICE 1990 & OFFICE 2010 \\
\hline COMPANY & Individual & $\begin{array}{l}\text { Corporate / } \\
\text { conglomeration }\end{array}$ & Specialist / system \\
\hline SYSTEM & Typewritter & Computer & Laptop/Tab/Cellphone \\
\hline $\begin{array}{l}\text { INFORMATION } \\
\text { WORKFLOW }\end{array}$ & Mail Room & Intranet & Internet/cloud \\
\hline FURNITURE & Workstation & Cubical & Shearing \\
\hline $\begin{array}{l}\text { TYPE OF } \\
\text { WORK }\end{array}$ & Individual & Group & Network \\
\hline OPERATIONAL & Hierarchy (from & $\begin{array}{l}\text { Specialist (everybody } \\
\text { has their own }\end{array}$ & $\begin{array}{l}\text { Co-Working } \\
\text { (specialist + specialist is } \\
\text { power) }\end{array}$ \\
\hline $\begin{array}{l}\text { POSITION OF } \\
\text { EMPLOYEE }\end{array}$ & Zone desk) & meaning) & Mobile - equality \\
\hline SITE & Specific & Centralized & Anywhere Connected \\
\hline THEME & Rigid & Corporate & Playful \\
\hline IMAGE & Strong & Power & Homey \\
\hline
\end{tabular}

Tabel 2. Perkembangan Tipologi Kantor

\section{Pengertian Videoblogging}

Blog video (bahasa Inggris: video-Blogging, atau bisa disingkat "vlog" atau vlogging (diucapkan "vlogging", bukan "v-logging"), atau vidblogging, merupakan suatu bentuk kegiatan blogging dengan menggunakan medium video di atas penggunaan teks atau audio sebagai sumber media perangkat seperti ponsel berkamera, kamera digital yang bisa merekam video, atau kamera murah yang dilengkapi dengan mikrofon merupakan modal yang mudah untuk melakukan aktivitas blog video. Blog video sendiri dapat dibuat dalam bentuk rekaman satu gambar atau rekaman yang dipotong ke beberapa bagian. Dengan perangkat lunak yang tersedia, seseorang dapat menyunting video yang mereka buat dan memadukannya dengan audio, serta menggabungkan beberapa rekaman ke dalam satu gambar, sehingga menjadi suatu rekaman blog video yang padu. 


\section{METODE}

Dari teori-teori di atas maka tebentuklah penerapan penerapan design yang muncul :

a. Metode survey lapangan

b. Metode Shape Grammar

c. Metode Green Architecture

\section{DISKUSI DAN HASIL}

\section{Survey Lapangan}

Survey lapangan dilakukan untuk melihat keadaan tapak eksisting dan menganalisa fenomena-fenomena yang ada di sektira tapak terpilih. Selain itu harus diperhatikan juga peruntukan tanah dari tapak yang terpilih agar sesuai dengan fungsi yang akan dibuat.

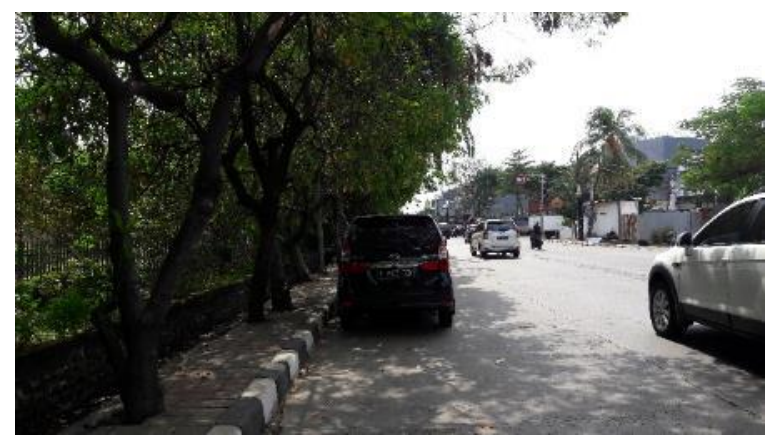

Gambar 1. TOD

Sumber : Penulis, 2019

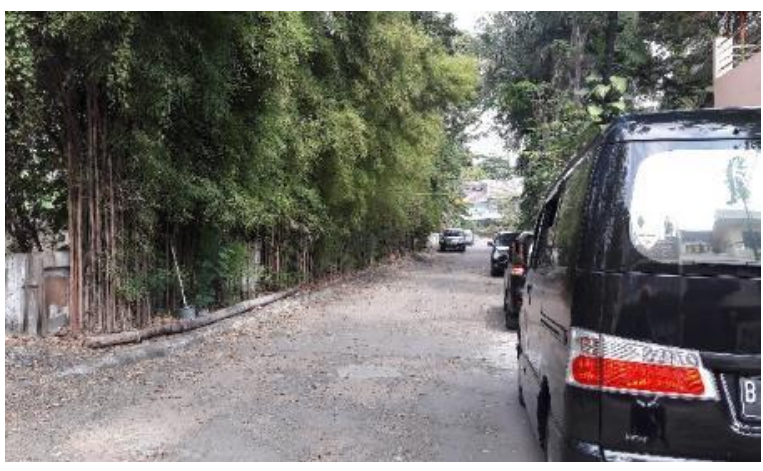

Gambar 3. Jalur Pedestrian Sumber : Penulis, 2019

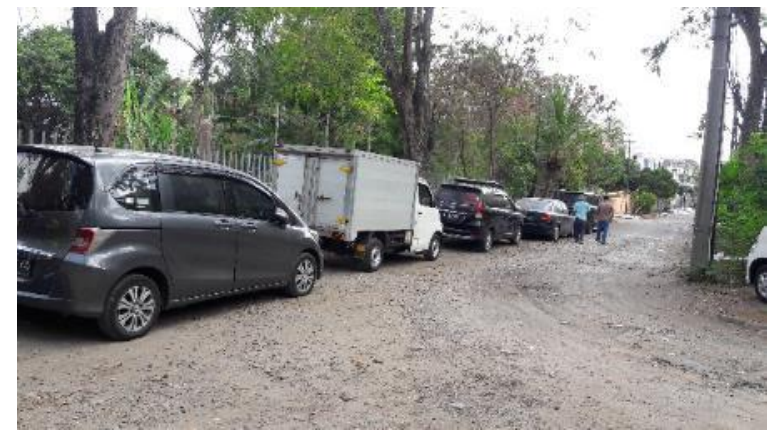

Gambar 2. Jalur Pedestrian Sumber : Penulis, 2019

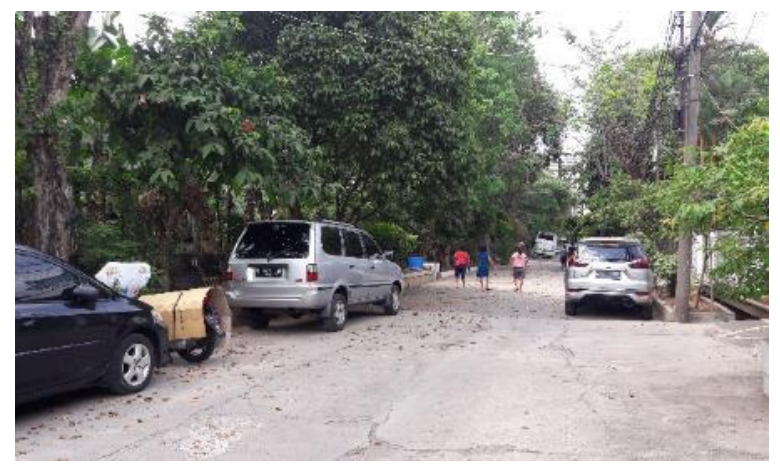

Gambar 4. Jalur Pedestrian Sumber : Penulis, 2019

Dari keadaan existing yang ada di lapangan, sangat memungkinan sekali untuk membangun proyek ini di tapak tersebut, karena dekat dengan TOD dan banyak aktivitas generasi millennials di daerah Muara Karang, serta memiliki akses di jalan utama (JI. Muara Karang Raya). Selain itu kurangnya akses dari dalam kompleks ke jalan arteri. Oleh karena itu akan dibuat passage pada proyek ini. Orientasi bangunan akan dihadapkan di jalan utama. Peruntukan tanah yang ada pada tapak ini menuntut koefisien dasar hijau sebesar $45 \%$ sehingga, akan tercipta banyak ruang publik yang berada diluar tapak. Ruang-ruang publik tersebut akan menjadi pengikat bangunan pada sekitarnya yaitu perumahan muara karang, ruang publik yang tercipta di luar bangunan sebagai penyambut untuk masuk ke bangunan utama. 


\section{Shape Grammar}

Metode ini berhubungan dengan fungsi yang akan dibuat pada proyek ini, dimana proyek ini mengadopsi sebuah tipologi, yaitu tipologi kantor, dimana tipologi kantor memiliki bentuk dan aturannya tersendiri, oleh karena itu metode inilah yang akan menciptakan sebuah tipoologi baru bagi tipologi kantor untuk millennials. Metode ini memiliki keunikan tersendiri yaitu metode ini meiliki aturan-aturan yang harus dipatuhi dan tidak boleh dilanggar. Aturan-aturan tersbut lah yang akan menjadi sebuah tipologi baru bagi kantor di generasi millennials. Metode ini bukan hanya dilakukan pada penemuan tipologi baru, tetapi metode ini juga digunakan untuk membuat sebuah gubahan massa yang cocok untuk generasi millennials.

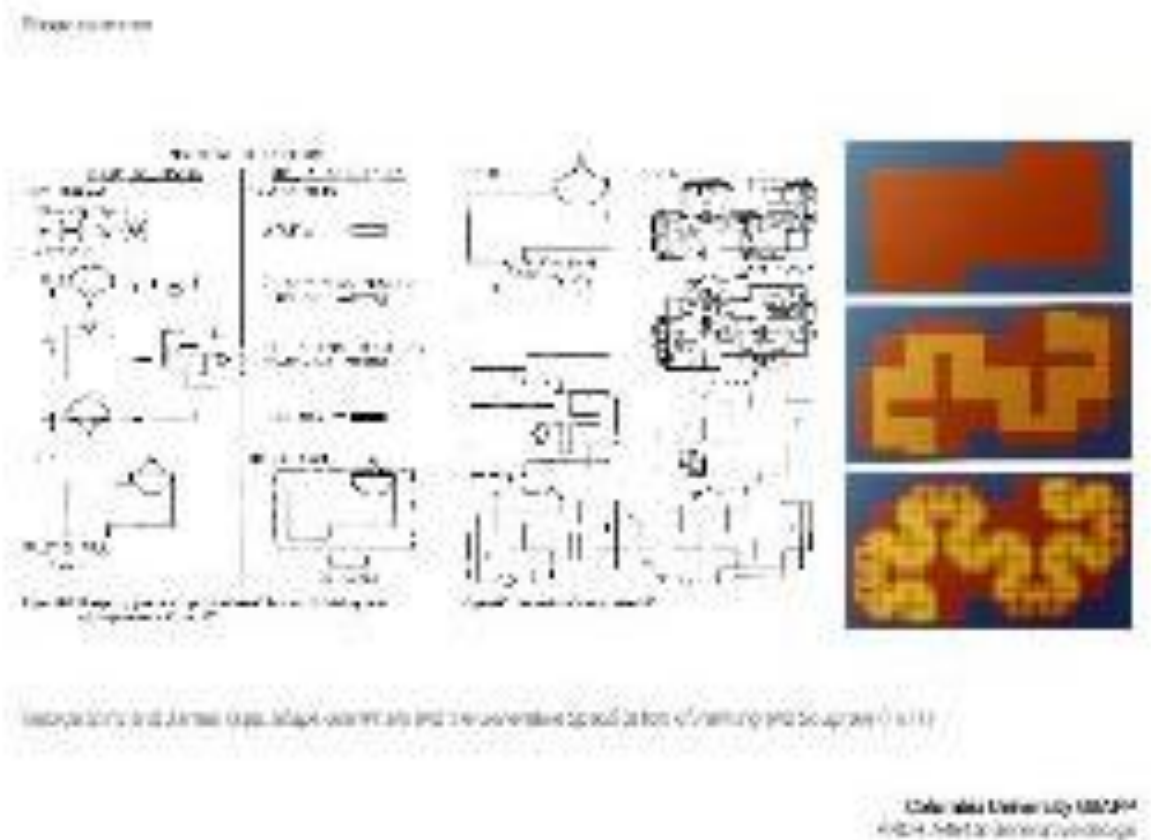

Gambar 5. Shape Grammars and the Generative specification of painting and sculpture Sumber: researchgate.net

\section{Green Architecture}

Menurut Kwok Allison dalam Ming Kok, Cheah tahun 2008, Green Architecture adalah sebuah proses perancangan dalam mengurangi dampak lingkungan yang kurang baik, meningkatkan kenyamanan manusia dengan meningkatkan efisiensi, dan pengurangan penggunaan sumber daya, energi, pemakaian lahan, dan pengelolaan sampah efektif dalam tataran arsitektur. Green Architecture merupakan konsep arsitektur yang berusaha meminimalkan pengaruh buruk terhadap lingkungan alam maupun manusia dan menghasilkan tempat hidup yang lebih baik dan lebih sehat, yang dilakukan dengan cara memanfaatkan sumber energi dan sumber daya alam secara efisien dan optimal. Green Architecture akan diterapkan di bagian fasad bangunan, bagian fasad pada bangunan akan ditumbuhi dengan tumbuhan yang bertujuan untuk meredam sinar matahari yang memancar secara langsung ke bangunan dan sebagai estetika fungsional pada bangunan tersebut. Selain itu terdapat rainwater harvesting sebagai sustainable design dan membuat kelembapan pada ruangan yang ada di sekitar wilayah rain harvesting tersebut. 


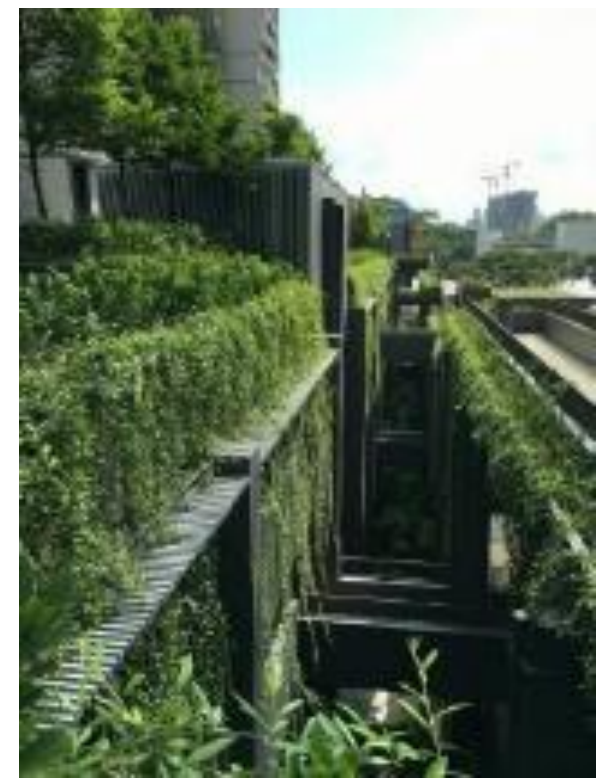

Gambar 6 : Green Facade Sumber : Pinterest Image

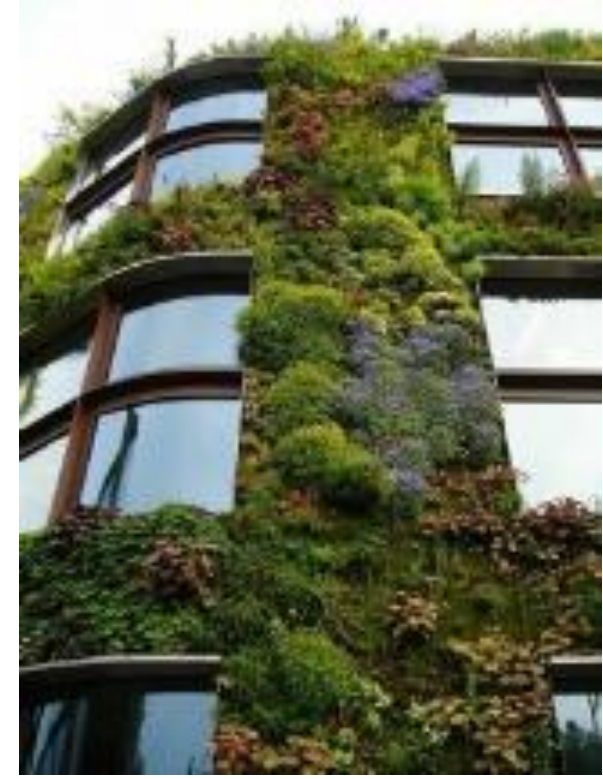

Gambar 7 : Green Facade Sumber : Pinterest Image

Berdasarkan hasil survey yang ada, maka terbentuklah sebuah konsep dan skema design yang lebih spesifik :

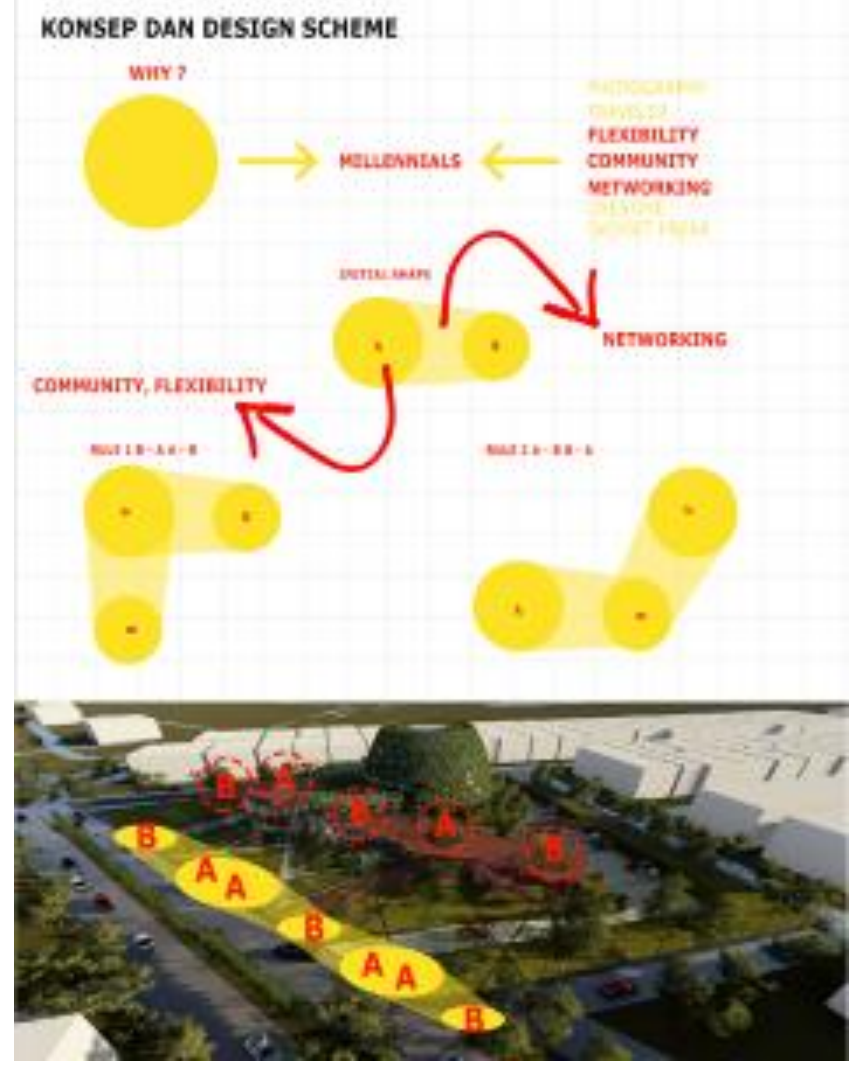

Gambar 8. Konsep

Sumber : Penulis, 2019

Konsep itu sendiri diambil dari salah satu karakteristik generasi millennials yaitu, fleksibel, komunitas, dan dan konektivitas. Dari kata kunci tersebut terlambanglah sebuah bentuk, yaitu 
bentuk lingkaran. Dari lingkaran tersebut maka diaplikasikanlah ke dalam metode yang terpilih yaitu shape grammar, dengan metode ini dapat terbentuk sebuah massa yang memiliki aturanaturan tertentu. Dari aturan-aturan tersebut akan terbentu sebuah massa. Dengan adanya 2 lingkaran yang disambungan dengan 2 garis linear yang melambangkan sebuah kontektivitas atar 2 individu atau lebih. Dari aturan-aturan yang sudah tercipta, aturan tersebut dapat di putar atau pun ditumpuk sesuai dengan peraturan yang sudah dibuat seperti yang dilampirkan pada gambar disamping.
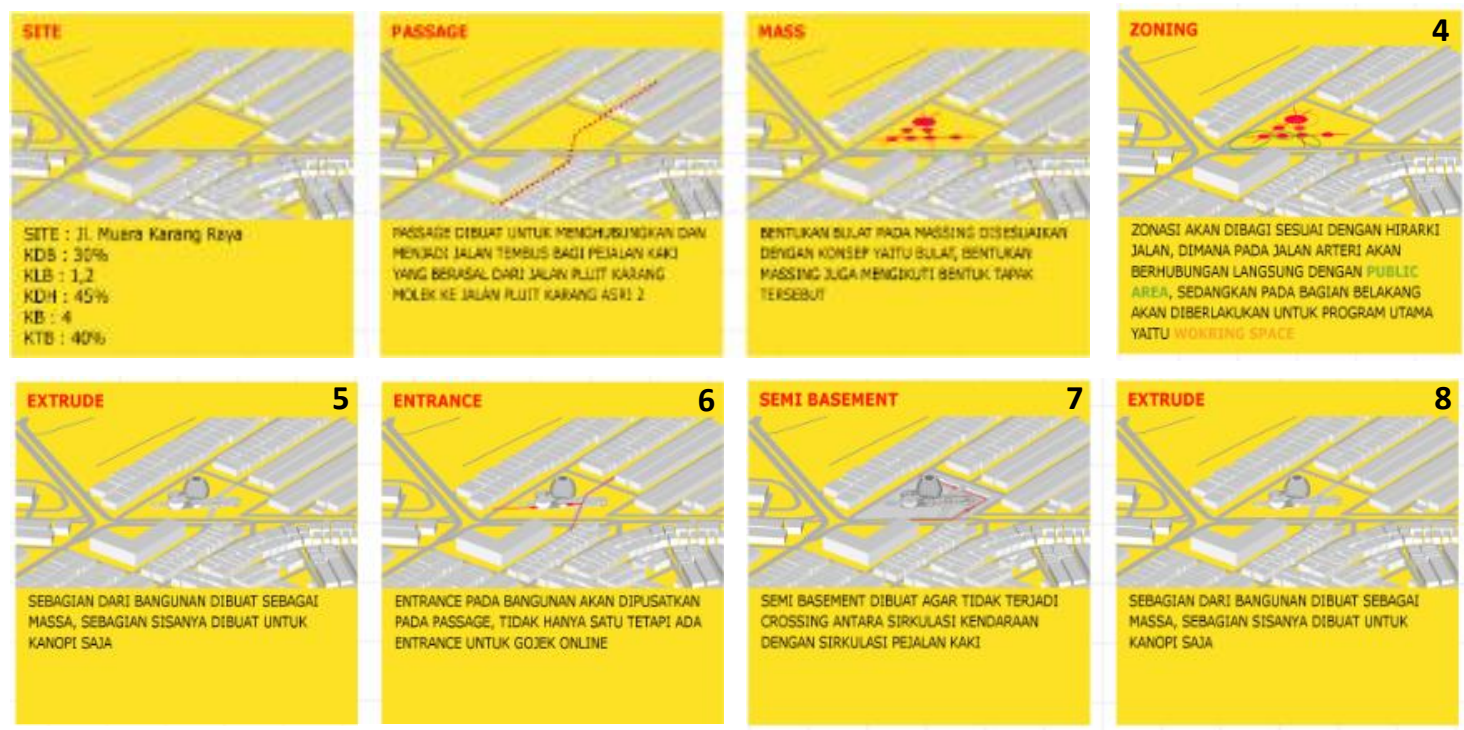

Gambar 9. Design Scheme

Sumber : Penulis, 2019

a. Ketentuan peruntukan pada tapak terdiri dari :

KDB : $30 \%$

KLB : 1,2

$\mathrm{KDH}: 45 \%$

$\mathrm{KB}: 4$

KTB : $40 \%$

b. Passage dibuat untuk menghubungkan dan menjadi jalan tembus bagi pejalan kaki yang berasal dari Jalan Pluit Karang Molek ke Jalan Pluit Karang Asri 2

c. Bentukan bulat pada massing disesuaikan dengan konsep, bentukan massing juga mengikuti bentuk tapak tersbut

d. Zonasi akan dibagi sesuai dengan hirarki jalan, dimana pada jalan arteri akan berhubungan langsung dengan ruang publik. Sedangkan bagian belakang akan berhubungan dengan ruang kerja.

e. Ditengah bangunan terdapat innercourt yang akan dijadikan sebagai rainwater harvesting

f. Entrance pada bangunan akan dipusatkan pada passage

g. Semi basement dibuat untuk menghindari crossing antara jalur pejalan kaki dengan jalur kendaraan

h. Sebagaian dari zoning tersebut akan dibentuk dari menjadi massa, ada yang menjadi massa dan ada yang menjadi kanopi saja 


\section{KESIMPULAN DAN SARAN}

Dengan mendesain sebuah bangunan berdasarkan tipologi dan prilaku generasi millennial maka kita akan menciptakan sebuah bangunan yang sangat cocok untuk generasi millennial. Tipologi bukan hanya berdasarkan bentuk bangunan, tetapi tipologi juga bias dilihat dari denah ataupun sifat generasi millennial, dengan prilaku generasi millennial yang bersifat tebuka dan senang untuk berdiskusi, oleh karena itu ruang kerja yang akan diciptakamn akan lebih bersifat terbuka agar dapat terjadi diskusi antar individu. Sedangkan dari sisi eksterior juga dapat diterapkan prinsip Green Architecture dimana Green Architecture bukan hanya sekedar memberikan kesan bangunan akan lebih sustain tetapi dengan elemen-elemen tertentu yang dimiliki oleh sustainable development building akan tercipta sebuah estetika dari bangunan itu sendiri.

\section{REFERENSI}

Dini. (2017). Dampak Positif dan Negatif Penggunaan Teknologi Informasi dan Komunikasi, dipetik 9 Juli 2019<https://dosenit.com/kuliah-it/teknologi-informasi/dampak-positif-dannegatif-penggunaan-teknologi-informasi-dan-komunikasi

Igogokil. (2014). Perkembangan dan Kemajuan Teknologi Era Sekarang, dipetik 9 Juli 2019,<https://igogokil.wordpress.com/2014/07/09/perkembangan-dan-kemajuanteknologi-era-sekarang/

KOMINFO. (2019) Ekonomi Kreatif adalah Pilar Perekonomian Masa Depan, dipetik 9 Juli 2019<https://kominfo.go.id/content/detail/5277/ekonomi-kreatif-adalah-pilarperekonomian-masa-depan/0/berita

Lurintya, Y. (2017) Kemajuan Teknologi di Era Modern, dipetik 9 Juli 2019<http://yusnialaurintya.student.umm.ac.id/2017/08/10/b-kemajuan-teknologi-di-eramodern/

Pengertian Kantor, dipetik 9 Juli 2019<https://kbbi.web.id/kantor; .

Rumah, P. 2017, Siapa itu Generasi Millennial, dipetik 8 Maret 2019,<http://rumahmillennials.com/siapa-itu-generasi-millenials/\#.XFee8PZuKHs

Putra, S. Y. (2016). Theoritical Review : Teori Perbedaan Generasi. 124-132

Skinner, B.F. (1938). The Behavior of Organisms: An Experimental Analysis. Cambridge, Massachusetts: B.F. Skinner Foundation. ISBN 1-58390-007-1

Wajong, D. R. F. (2018). Penerapan Green Atchitecture sebagai Upaya Pencapaian Sustainable Architecture. 5-25 
